\title{
Living-donor liver transplantation for giant hepatic hemangioma with diffuse hemangiomatosis in an adult: a case report
}

\author{
Ju Hyun Lee', Chang Jin Yoon ${ }^{1}$, Young Hoon Kim², Ho-Seong Han², Jai Young Cho ${ }^{3}$, Haeryoung Kim, Eun Sun Jang', \\ Jin-Wook Kim', and Sook-Hyang Jeong' \\ Departments of ${ }^{1}$ Internal Medicine, ${ }^{2}$ Radiology, ${ }^{3}$ Surgery, and ${ }^{4}$ Pathology, Seoul National University Bundang Hospital, College of \\ Medicine, Seoul National University, Seongnam, Korea
}

\begin{abstract}
Hepatic hemangioma represents the most common benign primary hepatic neoplasm. Although most such tumors are small and asymptomatic, giant hepatic hemangioma is frequently symptomatic, and requires intervention. Moreover, diffuse multiple hepatic hemangiomatosis occupying almost the entire liver is extremely rare in adults, and the optimal management for this condition is unclear. We report a case of a rapidly growing, symptomatic giant hepatic hemangioma with diffuse hepatic hemangiomatosis in a 50-year-old female patient who was treated by living-donor liver transplantation. This case shows malignant behavior of a benign hemangioma that required liver transplantation. Although this case could not meet the criteria for transplantation according to the MELD (model for end-stage liver disease) score system, it should be considered as an exceptional indication for deceased-donor liver allocation. Further studies of the mechanism underlying hemangioma growth are warranted. (Clin Mol Hepatol 2018;24:163-168)
\end{abstract}

Keywords: Hemangioma; Hemangiomatosis; Hepatic neoplasm; Liver transplantation

\section{INTRODUCTION}

Hemangioma represents the most common benign hepatic neoplasm, with an estimated prevalence of 0.4 to $20 \%$ based on autopsy series. ${ }^{1,2}$ Most hemangiomas are small, asymptomatic and detected incidentally. They are commonly detected in women with a female: male ratio of up to $5: 1$, and are more prevalent in the third and fifth decades.' Giant hepatic hemangiomas, defined as hemangiomas larger than $4-5 \mathrm{~cm}$, are frequently symptomatic and require intervention. Despite being pathologically benign, some hemangiomas grow in size by unclear mechanisms, and may be difficult to differentiate from malignant vascular tumors such as angiosarcomas. Moreover, diffuse hepatic hemangiomatosis usually presents in infancy with Rendu-Osler Weber disease or skeletal hemangiomatosis. ${ }^{3}$ Isolated diffuse hepatic hemangiomatosis without extrahepatic lesions is extremely rare in adults. We experienced a case of living donor liver transplantation in a 50 year old female patient with hepatic hemangiomatosis and hepatic hemangioma with increased size and symptoms. Herein, we report this case with a review of literature.

\section{Abbreviations:}

$\mathrm{CT}$, computed tomography; MELD, model for end-stage liver disease

\section{Corresponding author: Sook-Hyang Jeong}

Department of Internal Medicine, Seoul National University Bundang Hospital, 82 Gumi-ro 173beon-gil, Bundang-gu, Seongnam 13620, Korea Tel: +82-31-787-7029, Fax: +82-31-787-4052

E-mail: jsh@snubh.org

http://orcid.org/0000-0002-4916-7990 


\section{CASE REPORT}

In May $27^{\text {th }}$, 2015, a 50 year old Korean woman was admitted due to dyspnea, abdominal pain and a palpable huge mass. At a previous routine health check in October $28^{\text {th }}, 2010$, a $10 \mathrm{~cm}$-sized giant hepatic hemangioma and several tiny hemangiomas less than $1 \mathrm{~cm}$ in diameter were incidentally detected on ultrasonography and on subsequent abdominal computed tomography (CT) (Fig. 1). However, she did not follow up the lesion after then. She didn't smoke or drink alcohol. Her medical history and familial history were unremarkable. She denied recent or remote estrogen administration or any other medications.

On admission, physical examination showed pale conjunctiva, and tender hepatomegaly which was palpated as palm breadth below the right costal margin. The laboratory tests showed hemoglobin level of $9.3 \mathrm{~g} / \mathrm{dL}$ (MCV $77 \mathrm{fl}, \mathrm{MCH} 23.8 \mathrm{pg}$ ), platelet count of $123,000 / \mathrm{mm}^{3}$, total bilirubin of $0.4 \mathrm{mg} / \mathrm{dL}$, alkaline phosphatase of $62 \mathrm{IU} / \mathrm{L}$, gamma-glutamyl transpeptidase of $58 \mathrm{IU} / \mathrm{L}$, aspartate transaminase of $28 \mathrm{IU} / \mathrm{L}$, alanine transaminase of $20 \mathrm{IU} / \mathrm{L}$, and a prothrombin time of 15.9 seconds, showing mild KasabachMerritt syndrome. Hepatitis B and C virus markers were negative and alpha feto-protein level was within normal range.

An abdomen CT taken on May 28 ${ }^{\text {th }}$, 2015 demonstrated a $16 \mathrm{~cm}$ sized giant hemangioma in the central portion of the liver collapsing the inferior vena cava and heterogeneous nodular enhancement in the whole liver, with increased size and numbers of hemangiomas compared with the previous CT taken at 2010 (Fig. 2). T2-weighted MR images demonstrated a huge mass with late, pe-
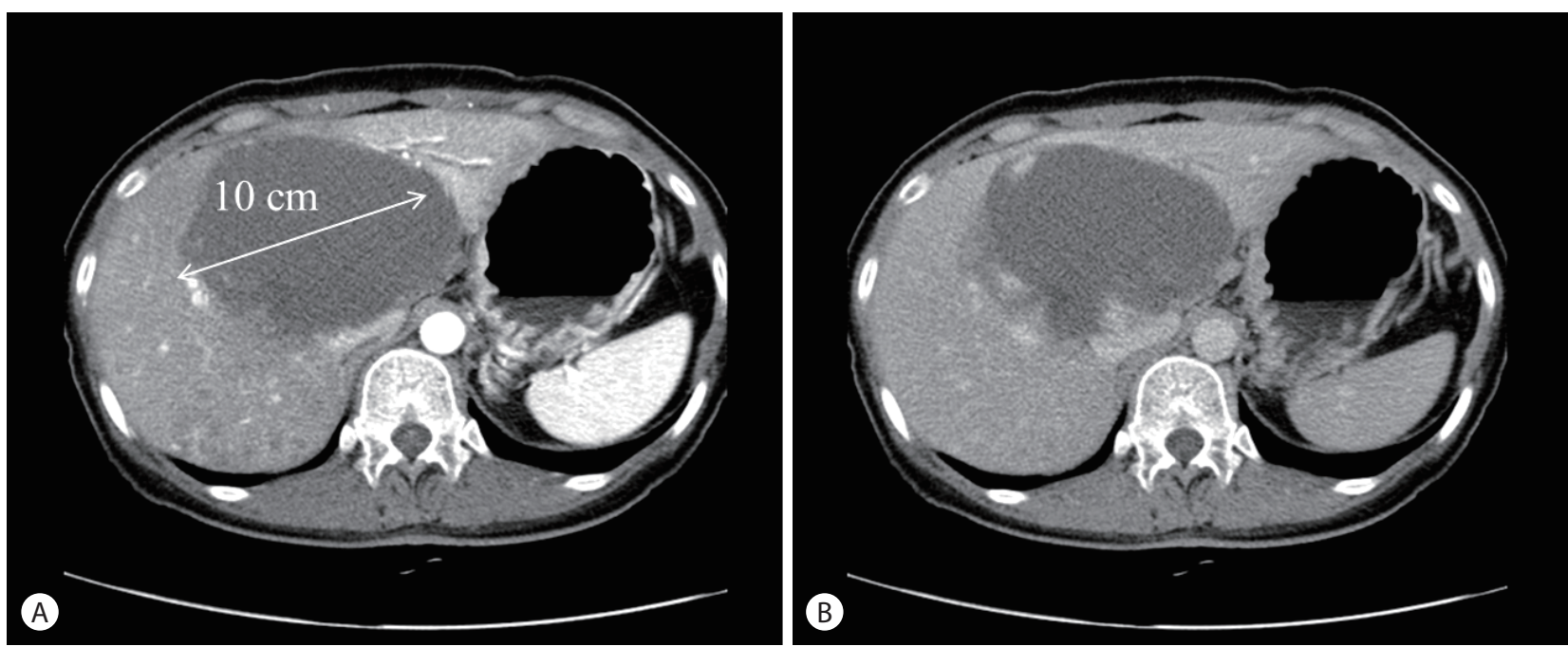

Figure 1. Initial CT scan of the abdomen and pelvis obtained on October 28, 2010. A huge (10-cm) hemangioma is evident in the central portion of the liver, with multiple disseminated small enhanced nodular lesions in the right hemiliver (A: arterial phase, B: delayed phase).
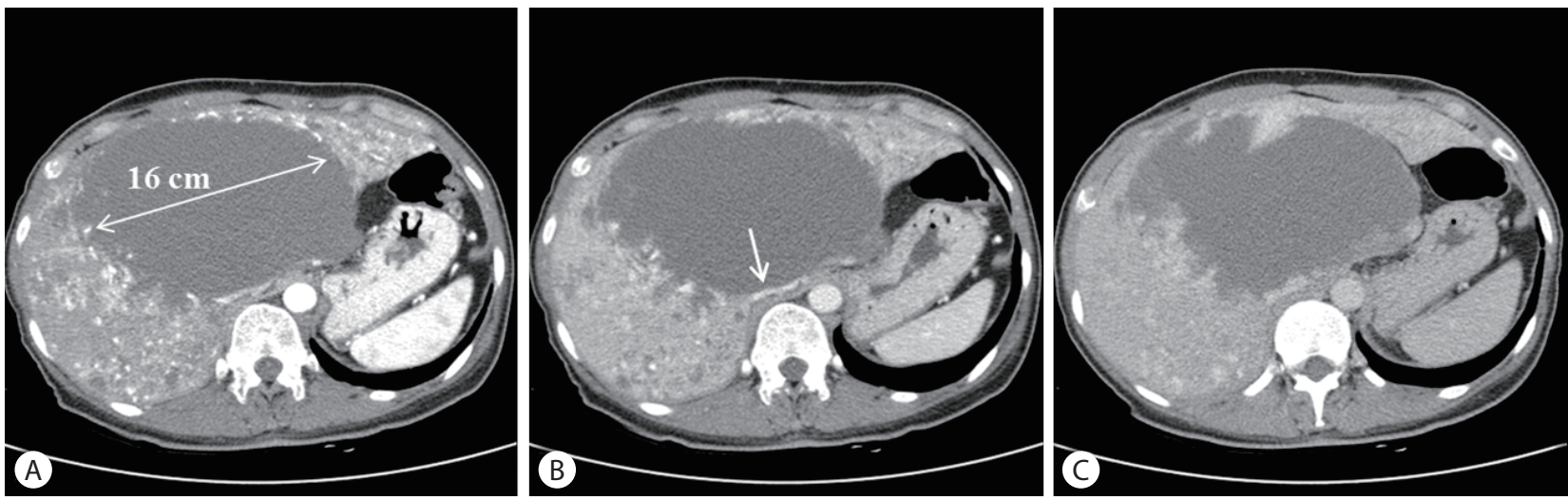

Figure 2. Follow-up CT scan of the abdomen and pelvis obtained on May 28, 2015. The mass in the central liver has enlarged, and numerous enhanced nodular lesions are disseminated in both hemilivers. The inferior vena cava (arrow) is massively dislocated to the left and slit-shaped due to compression (A: arterial phase, B: portal phase, C: delayed phase). 

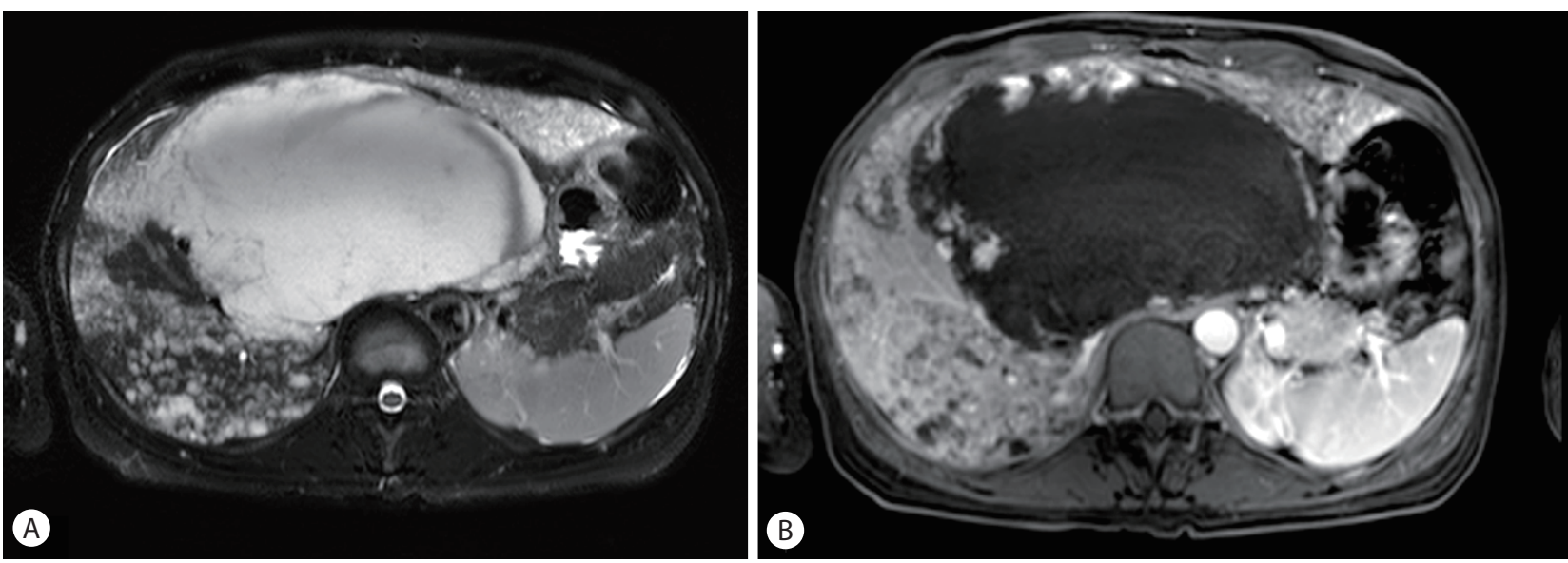

Figure 3. Liver MRI image obtained on June 3, 2015. T2-weighted MRI image shows the enlarged huge mass with a high signal intensity involving segments 1, 4, 7 and 8 of the liver. The extents of disseminated small enhanced lesions are increased (A: T2-weighted image, B: contrast-enhanced T1weighted image).
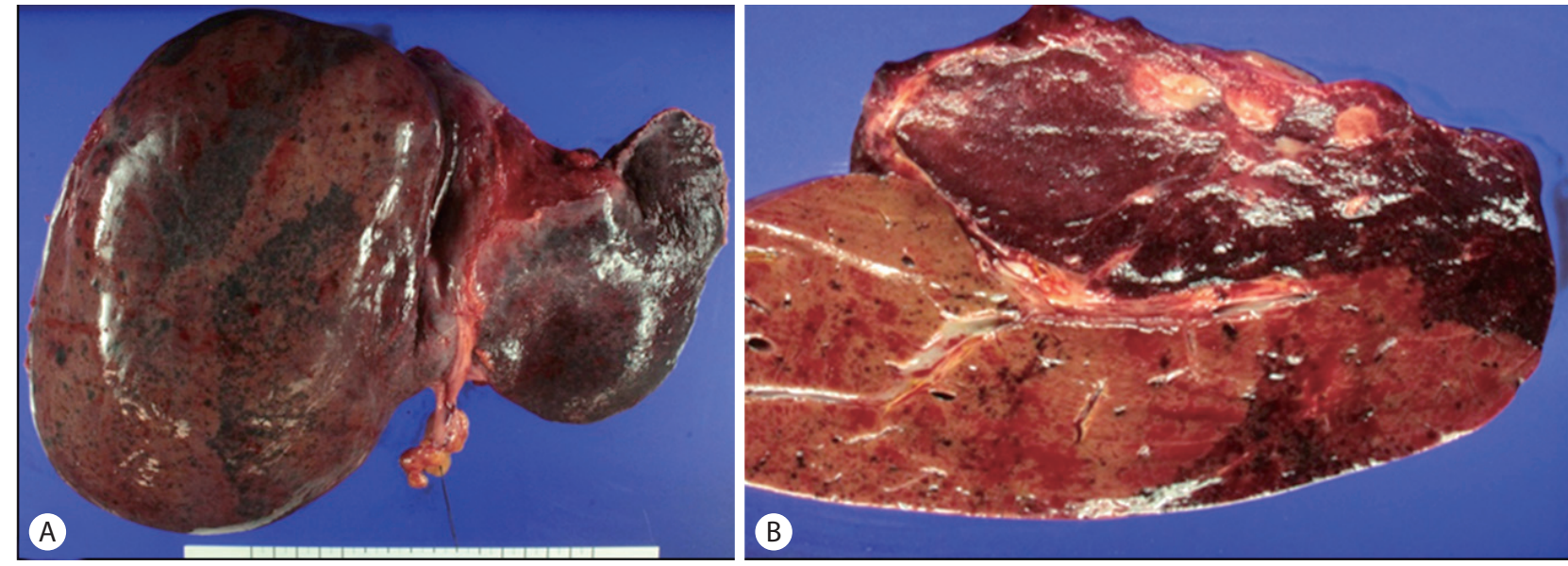

Figure 4. The explanted liver showing multifocal patchy brownish discoloration. A representative section (A) demonstrates a relatively well-demarcated sponge-like reddish-brown mass (upper right). The remaining hepatic parenchyme also demonstrates punctate reddish-brown lesions (B).

ripheral enhancement involving S1, 4, 7 and 8, and disseminated small enhancing lesions in the whole liver (Fig. 3). Fluorodeoxyglucose positron emission tomography (FDG-PET) scan showed a large mass with diffuse isometabolism in the liver without abnormal extrahepatic hypermetabolic lesions. Under the impression of growing hemangiomatosis, transcatheter arterial embolization was performed, with the aim of improving the symptoms and decreaseing the size of the mass. Selective hepatic artery angiography showed multiple hypervascular tumor stains in both hemiliver. Embolization was done with poly-vinyl alcohol particles (PVA) of size 45-150 $\mu \mathrm{m}$ and $3 \mathrm{~mm}$ coil via several subsegmental branches (two A4 from LHA, A5, A1, A7) from both hepatic artery. A postembolization check angiogram still noted multiple hypervascular stains of in both lobes.
Due to the patient's pain and the growing speed of the tumor suggesting impending rupture, and as the extensive hepatic involvement precluded surgical resection, the only option left was liver transplantation, despite the low likelihood of a malignant vascular tumor. The patient's son wanted to donate his liver to her, and therefore living donor liver transplantation was decided. The surgeons planned to use a femoro-axillary bypass circulation to avoid massive bleeding risk during huge hemangioma-containing recipient liver hepatectomy, to minimize potential dissemination of malignant tumor cells through inferior vena cava, and to prevent severe bowel edema or ischemia after blocking portal flow during total hepatectomy, especially in this patient without collateral vessels related to previous portal hypertension. On July $14^{\text {th }}, 2015$, liver transplantation using a modified right graft was 

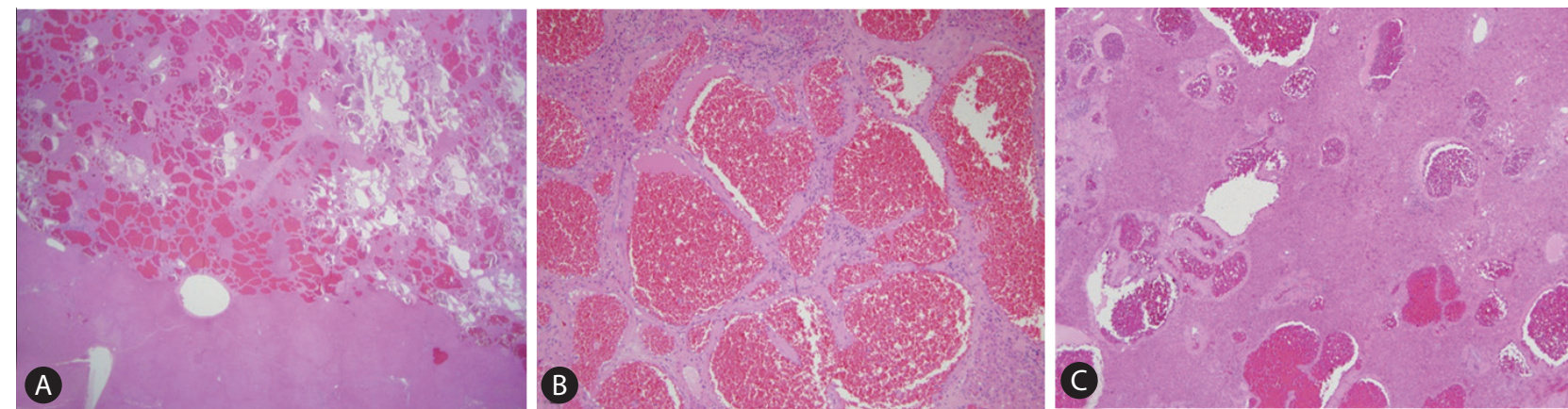

Figure 5. The main mass (A) is relatively well-demarcated from the surrounding liver, and is composed of variable-sized vascular spaces, lined by benign endothelial cells, consistent with hemangioma (B). Multiple scattered small hemangiomas are present in the surrounding hepatic parenchyme (C) (A: H\&E stain, $\times 10$ magnification; B: H\&E stain, ×200 magnification; C: H\&E stain, $\times 100$ magnification).

successfully performed under a femoro-axillary bypass system. The explanted liver weight was 2,344 $\mathrm{g}$ and the donor graft (right lobe) weighed $782 \mathrm{~g}$. The total operative time was 575 minutes and the estimated blood loss was 1,100 mL. Transfusion was not needed for this patient.

Pathological evaluation of the surgical specimen confirmed a well-defined hemangioma in the form of a sponge-like reddish brown mass, and the remaining liver parenchyma had a similar small lesions (Fig. 4, 5). She discharged on postoperative day 11 without any significant postoperative complications and is maintained on an immunosuppressive regimen of tacrolimus and mycophenolate in good health at the most recent follow up in December 2016.

\section{DISCUSSION}

Hepatic hemangioma is the most common benign liver tumors incidentally detected in the majority of patients. However, the differential diagnosis of hepatic hemagioma includes other hypervascular tumors such as hepatocellular adenoma, epithelioid hemangioendothelioma, angiosarcoma, hepatocellular carcinoma, metastatic neuroendocrine tumor or metastatic renal cell carcinoma. ${ }^{2}$ On the other hand, hepatic hemangiomatosis replacing the entire hepatic parenchyma is extremely rare in adults, while it is often reported in infants associated with Rendu-Osler Weber disease or skeletal hemangiomatosis. ${ }^{3}$ Diagnostic biopsies for hemangiomas are not recommended due to the risk of hemorrhage and difficulty in definitive diagnosis even after biopsy. ${ }^{4}$ Hepatic hemangiomas and hemangiomatosis are two separate entities with similar histological appearances. Co-existence of these entities in the same liver is rare and is described in the form of case reports. ${ }^{5}$

Because most hemangiomas maintain stable size without growth during follow-up more than 5 years, frequent follow-up imaging for hemangioma is not advised. ${ }^{2}$ However, the size of hepatic hemangioma increases in $10-20 \%$ of patients mostly due to vascular ectasia, leading to abdominal pain, intratumoral hemorrhage, rupture, compression of the biliary tree, cardiac failure from massive arteriovenous shunting or Kasabach-Merritt syndrome, which is characterized by consumptive coagulopathy presenting thrombocytopenia, microangiopathic hemolysis and disseminated intravascular coagulation. ${ }^{6}$ Although rupture of hemangioma is very rare, it results in a high mortality. A few studies suggested that estrogen therapy may influence the growth of hemangioma, however, most cases did not support such relationship.

The treatment of symptomatic giant hepatic hemangioma is controversial. Surgical intervention is strictly reserved for complications of hemangioma or uncertainty of malignancy. Considering the severity of symptoms as treatment indications, the benefits and risks of surgical treatment should be considered. The size of the tumor per se cannot be a definite indication for surgery. Surgical technique includes enucleation or resection, depending on the localization, size, and number of lesions, growth pattern and diagnostic uncertainty. Nonsurgical therapy such as transarterial embolization or radiofrequency ablation is used to reduce the size of hemangioma and the alleviate symptoms.

Awareness of the presence of hepatic hemangiomatosis in patient with giant hepatic hemangioma is important for therapeutic decision. When the tumor exceeds a certain volume in patients with limited hepatic reserve, liver resection is precluded. Despite its complexity, liver transplantation should be considered for nonresectable benign hepatic neoplasms in patients with imminent 
Table 1. Summary of the reported cases of liver transplantation for giant hepatic hemangioma

\begin{tabular}{|c|c|c|c|c|c|c|}
\hline $\begin{array}{l}\text { Report } \\
\text { no. }\end{array}$ & First author & Year & $\begin{array}{l}\text { Age/ } \\
\text { Sex }\end{array}$ & Graft type & Presentation & Results \\
\hline 1 & Klompmaker, et al. ${ }^{8}$ (1989) & 1989 & $27 Y / M$ & Whole & KMS & Alive, 3 years \\
\hline 2 & Mora, et al. ${ }^{9}(1995)$ & 1995 & $42 Y / F$ & Whole & KMS & Discharged, 16 days after operation \\
\hline 3 & Tepetes, et al..$^{10}(1995)$ & 1995 & $4 w k / M$ & Whole & KMS & Died, 8 days after operation \\
\hline 4 & Brouwers, et al." (1997) & 1980-1995 & 4 cases & Whole & 2pain, 1rupture, 1KMS & $\begin{array}{l}1 \text { Died, } 1 \text { months after op. } \\
3 \text { alive, } 9 \text { years }\end{array}$ \\
\hline 5 & Chui, et al. ${ }^{12}$ (1996) & 1996 & 2 cases & Whole & $\begin{array}{l}1 \text { bleeding } \\
1 \text { pain }\end{array}$ & $\begin{array}{l}1 \text { alive, } 18 \text { months } \\
1 \text { alive, } 14 \text { months }\end{array}$ \\
\hline 6 & Longeville, et al. ${ }^{13}$ (1997) & 1997 & 47Y/M & Whole & KMS & Alive, 12 months \\
\hline 7 & Russo, et al. ${ }^{14}(1997)$ & 1997 & $43 Y / F$ & Whole & & Discharged, 14 days after operation \\
\hline 8 & Kumashiro, et al. ${ }^{15}$ (2002) & 2002 & $48 Y / F$ & Posterior lobe & KMS & Discharged, 15 days after operation \\
\hline 9 & Ferraz, et al..$^{16}(2004)$ & 2004 & $25 Y / F$ & Whole & KMS & Alive, 30 months \\
\hline 10 & Meguro, et al. ${ }^{17}(2008)$ & 2006 & $45 Y / F$ & Left lobe & KMS & Alive, 10 months \\
\hline 11 & Zhong, et al. ${ }^{18}$ (2014) & 2007 & $27 Y / F$ & Right lobe & Diffuse mass & Alive, 50 months \\
\hline 12 & Vagefi, et al..$^{19}(2011)$ & 2010 & $39 Y / F$ & Whole & Rupture, KMS & Alive \\
\hline 13 & Yildiz, et al..$^{20}$ (2014) & 2014 & $44 Y / F$ & Whole & KMS & Alive, 1 months \\
\hline 14 & Lange, et al. ${ }^{21}$ (2015) & 2015 & $47 Y / F$ & Whole & Diffuse mass & Alive \\
\hline
\end{tabular}

KMS, Kasabach-Merritt syndrome.

life-threatening complications, an increased risk of malignant transformation, an underlying liver disease or the presence of severe symptoms. There have been 19 case reports of liver transplantation for giant hepatic hemangioma (Table 1), ${ }_{1}^{8-21}$ including ours, with excellent results.

Our case showed that unresectable, progressively growing tumors with diffuse whole liver involvement complicated with severe abdominal pain forecasting impending rupture, and imminent Kasabach-Merritt syndrome. The only option for cure was to offer liver transplantation, however, her hepatic function was normal according to the model for end-stage liver disease (MELD) score system, so that she could not be a candidate for deceased donor liver transplantation. Therefore, this kind of case represents one of non-standard exception status, which should be approved by the Korean Network for Organ Sharing (KNOS) in the future.

We report a case of a 50 year old female patient presenting with rapidly growing, symptomatic giant hepatic hemangioma with diffuse hepatic hemangiomatosis who underwent successful living donor liver transplantation. To our best knowledge, this rare case is the first Korean case showing a malignant behavior of a benign hemangiomatosis requiring liver transplantation. This case represented an exceptional indication of deceased donor liver allocation despite the low MELD score. Further studies on the mechanism of growing hemangioma are warranted.

\section{Conflicts of Interest}

The authors have no conflicts to disclose.

\section{REFERENCES}

1. Gandolfi L, Leo P, Solmi L, Vitelli E, Verros G, Colecchia A. Natural history of hepatic haemangiomas: clinical and ultrasound study. Gut 1991;32:677-680.

2. European Association for the Study of the Liver (EASL). EASL Clinical Practice Guidelines on the management of benign liver tumours. J Hepatol 2016;65:386-398.

3. Haitjema T, Westermann CJ, Overtoom TT, Timmer R, Disch F, Mauser $\mathrm{H}$, et al. Hereditary hemorrhagic telangiectasia (Osler-WeberRendu disease): new insights in pathogenesis, complications, and treatment. Arch Intern Med 1996;156:714-719.

4. Marrero JA, Ahn J, Reddy KR. ACG clinical guideline: the diagnosis and management of focal liver lesions. Am J Gastroenterol 2014;109:1328-1347.

5. Maeda E, Akahane M, Watadani T, Yoshioka N, Goto A, Sugawara $Y$, et al. Isolated hepatic hemangiomatosis in adults: Report of two cases and review of the literature. Eur J Radiol Extra 2007;61:9-14.

6. Kasabach HH, Merritt KK. Capillary hemangioma with extensive purpura: report of a case. Am J Dis Child 1940;59:1063-1070.

7. Schweigerer L, Pavlakovic H, Havers W. Infantile liver hemangiomatosis: evidence for molecular heterogeneity. J Pediatr 2000;136:419-420. 
8. Klompmaker IJ, Sloof MJ, van der Meer J, de Jong GM, de Bruijn $\mathrm{KM}$, Bams JL. Orthotopic liver transplantation in a patient with a giant cavernous hemangioma of the liver and Kasabach-Merritt syndrome. Transplantation 1989;48:149-151.

9. Mora A, Cortés C, Roigé J, Noguer M, Camps MA, Margarit C. [Orthotopic liver transplant for giant cavernous hemangioma and Kasabach-Merritt syndrome]. Rev Esp Anestesiol Reanim 1995;42:71-74.

10. Tepetes K, Selby R, Webb M, Madariaga JR, Iwatsuki S, Starzl TE. Orthotopic liver transplantation for benign hepatic neoplasms. Arch Surg 1995;130:153-156.

11. Brouwers MA, Peeters PM, de Jong KP, Haagsma EB, Klompmaker IJ, Bijleveld CM, et al. Surgical treatment of giant haemangioma of the liver. Br J Surg 1997;84:314-316.

12. Chui AK, Vass J, McCaughan GW, Sheil AG. Giant cavernous haemangioma: a rare indication for liver transplantation. Aust N Z J Surg 1996;66:122-124.

13. Longeville JH, de la Hall P, Dolan P, Holt AW, Lillie PE, Williams $J A$, et al. Treatment of a giant haemangioma of the liver with Kasabach-Merritt syndrome by orthotopic liver transplant. HPB Surg 1997;10:159-162.

14. Russo MW, Johnson MW, Fair JH, Brown RS Jr. Orthotopic liver transplantation for giant hepatic hemangioma. Am J Gastroenterol 1997;92:1940-1941.

15. Kumashiro Y, Kasahara M, Nomoto K, Kawai M, Sasaki K, Kiuchi
T, et al. Living donor liver transplantation for giant hepatic hemangioma with Kasabach-Merritt syndrome with a posterior segment graft. Liver Transpl 2002;8:721-724.

16. Ferraz AA, Sette MJ, Maia M, Lopes EP, Godoy MM, Petribú AT, et al. Liver transplant for the treatment of giant hepatic hemangioma. Liver Transpl 2004;10:1436-1437.

17. Meguro M, Soejima Y, Taketomi A, Ikegami T, Yamashita Y, Harada $\mathrm{N}$, et al. Living donor liver transplantation in a patient with giant hepatic hemangioma complicated by Kasabach-Merritt syndrome: report of a case. Surg Today 2008;38:463-468.

18. Zhong L, Men TY, Yang GD, Gu Y, Chen G, Xing TH, et al. Case report: living donor liver transplantation for giant hepatic hemangioma using a right lobe graft without the middle hepatic vein. World J Surg Oncol 2014;12:83.

19. Vagefi PA, Klein I, Gelb B, Hameed B, Moff SL, Simko JP, et al. Emergent orthotopic liver transplantation for hemorrhage from a giant cavernous hepatic hemangioma: case report and review. J Gastrointest Surg 2011;15:209-214.

20. Yildiz S, Kantarci M, Kizrak Y. Cadaveric liver transplantation for a giant mass. Gastroenterology 2014;146:e10-e11.

21. Lange UG, Bucher JN, Schoenberg MB, Benzing C, Schmelzle M, Gradistanac T, et al. Orthotopic liver transplantation for giant liver haemangioma: A case report. World J Transplant 2015;5:354-359. 